\title{
Coletivo De Mulheres Universitárias: Nova Forma De Fazer Política Feminista? Uma Análise Utilizando Process-tracing Sobre A Criação Dos Coletivos Universitários No Contexto Da Puc-rio.
}

Collective Of University Women: A New Way Of Doing Feminist Politics? An Analysis Using Process-tracing On The Creation Of University Collectives In The Context Of Puc-rio.

\author{
Elaine de Azevedo Maria ${ }^{1}$ \\ Sonia Maria Giacomini ${ }^{2}$
}

\section{RESUMO}

Este artigo tem como objetivo demonstrar a relação do coletivo de mulheres da PUC-Rio com a modificação na política acadêmica desta universidade e a criação de novos coletivos. A metodologia escolhida foi o process-tracing por ter estrutura de rastreamento causal que permite analisar, através da sequência dos acontecimentos, o processo de construção política do movimento acadêmico.

PALAVRAS-CHAVE: Mulheres na política, Coletivos universitários, Process-tracing.

\begin{abstract}
This article has the objective of demonstrating the relationship of the women's group of PUC-Rio with the modification in academic policies at this university and the creation of new groups. Process-tracing was the chosen methodology, given that tracking causal factors is the structure of this method, allowing for analysis of the process of political construction in the academic movement through the sequence of events.
\end{abstract}

KEYWORDS: Women in politics, University groups, Process-tracing

Formada em Direito pela UFRJ , mestra em Ciências Sociais da PUC-Rio. E-mail: elainemaria@puc-rio.com; Currículo Lattes: http://lattes.cnpq.br/6303484448870115

2 Professora titular e pesquisadora da PUC-Rio e Doutora pelo IUPERJ. E-mail sgiacom@puc-rio.br;

Currículo Lattes: http://lattes.cnpq.br/7116654995233760 


\section{INTRODUÇÃO}

Pretende-se evidenciar a importância do coletivo de mulheres (CM) da PUC-Rio (Pontifícia Universidade Católica do Rio de Janeiro) na política universitária e no desenvolvimento das habilidades políticas de suas integrantes. Para tanto a metodologia escolhida foi o process-tracing por ter estrutura de rastreamento causal. Esta pesquisa foi realizada no percurso do mestrado da primeira autora e a segunda autora foi a orientadora. Deseja-se compreender, através da sequência dos acontecimentos, as autoras e os autores que motivaram a criação dos coletivos universitários dentro desta universidade.

Este artigo foi escrito durante a fase de entrevistas para a dissertação. Estas foram utilizadas para analisar os acontecimentos históricos e a influência do CM na criação dos outros coletivos universitários. Como a etapa da pesquisa na época em que este artigo foi escrito era de coleta de dados e por não ser o objetivo aqui, limito a utilizar as minhas inferências e impressões sobre as entrevistas e não transcrevê-las. Como exemplo, cito que o coletivo se fortaleceu após a organização da semana internacional da mulher de 2015. Esta informação não está vinculada a nenhuma entrevista neste presente trabalho. Isto porque, neste artigo, o foco principal não é a análise das entrevistas. Apenas cito esta informação por ser relevante para a análise política.

Inicialmente analisarei a transformação do movimento estudantil. Em seguida apresentarei o método process-tracing e finalmente analisarei o caso da PUC-Rio, onde o CM foi pioneiro.

\section{AS MODIFICAÇÕES DOS MOVIMENTOS DE MOBILIZAÇÃO POLÍTICA UNIVERSITÁRIA}

Até o início do século XXI a política estudantil dentro da PUC-Rio era composta por Centros Acadêmicos (CA) de diversos cursos existentes na universidade e pelo Diretório Central dos Estudantes (DCE). Os movimentos sociais no Brasil presenciaram um novo dinamismo após o início da redemocratização brasileira, com pauta na agenda pública voltada para questões específicas ligadas à maior justiça social e com os movimentos sociais que se organizaram para cobrar a solução dos déficits dos mais variados tipos de Direitos Humanos (PAIVA, 2014). Neste contexto, o ambiente universitário também teve sua estrutura reivindicatória alterada. Os CAs e o 
DCE eram a única forma ${ }^{3}$ que os estudantes usavam para realizar suas reivindicações perante a própria universidade e suas manifestações políticas. Suas estruturas são representativas, através de eleições periódicas onde grupos de alunos se candidatam e o mais votado assume a diretoria do CA, com cargos pré-definidos e buscam cumprir o que foi estipulado na campanha eleitoral.

Todavia verifica-se a alteração na estrutura dos movimentos estudantis com a proliferação dos Coletivos, onde não há hierarquia entre os membros, eleições ou mandato. O coletivo não possui um representante, pois todos os membros atuam de forma direta nas decisões do grupo. No site do DCE podemos ver a definição: "Os coletivos são formados por estudantes que possuem opiniões, ideias e pautas em comum sobre a universidade e a sociedade em geral" (PUC-Rio, 2017). É necessário ressaltar, todavia, que os Coletivos não acabaram com os CAs, estes dois movimentos existem atualmente na PUC-Rio. Verifica-se que existem nove Coletivos e vinte CAs (PUC-Rio, 2017), todavia os CAs são todos antigos na estrutura do DCE e os coletivos são novos e estão aumentando cada vez mais entre os estudantes.

De acordo com Paiva (2014) convencionou-se a chamar de "novos" movimentos sociais aqueles cujas reivindicações não estão relacionadas nem à classe nem aos sindicatos e tão pouco a partidos políticos. Desse modo, o conceito da autora aproxima da proposta dos Coletivos. Além disso, percebe-se a forma e o lugar que os grupos se encontram para debater, interagir e deliberar são convergente com a forma que a nova juventude interage.

Ressaltamos também que a educação não se resume à educação escolar, realizada na escola propriamente dita. "Há aprendizagens e produção de saberes em outros espaços, aqui denominados de educação não formal” (Gohn, 2011, p.333). Este conceito amplo do que é educação abarca os coletivos universitários, pois percebemos nele uma contribuição única e fundamental para a formação universitária. Gohn diz "há um caráter educativo nas práticas que se desenrolam no ato de participar, tanto para os membros da sociedade civil, como para a sociedade mais geral, e também para os órgãos públicos envolvidos - quando há negociações, diálogos ou confrontos (GOHN, 2011, p.333)”.

E percebemos que os coletivos universitários podem ser enquadrados de forma precisa neste seu conceito. Este novo movimento social contribui para a formação político-social do estudante, além de estimular o respeito, a escuta e o diálogo.

\footnotetext{
3 As Atléticas são também organizações universitárias antigas na PUC-Rio, todavia por serem mais voltadas para a promoção de festas e campeonatos esportivos e não terem pauta política preferiu-se não abordá-las neste trabalho.
} 


\section{UTILIZANDO O PROCESS-TRACING}

Para entender o processo de mudança na estrutura política do cenário desta universidade foi realizado o estudo pelo método das ciências sociais chamado process-tracing, onde relacionamos os acontecimentos históricos. O método consiste em buscar relações causais em uma série sequencial de eventos, mostrando, assim, qual evento gerou outro até se chegar ao evento final desejado. O esquema gráfico do process-tracing está no anexo 1 deste artigo.

O objetivo é perceber as influências do CM na criação dos coletivos universitários e nesta mudança de forma de política estudantil. Para tal dividimos os acontecimentos em 5 categorias: repercussão na mídia, eventos dentro da PUC-Rio, protestos, criação dos coletivos universitários e DCE. Chamaremos cada categoria de módulo e a sequência dos acontecimentos dentro desses módulos será cronológica.

É ímpar ressaltar que os fatos ocorridos na PUC-Rio historicamente repercutem de forma intensa e veloz na mídia carioca. Alguns fatores como a proximidade geográfica com a sede da Rede Globo e a presença de personalidades políticas e midiáticas - e seus filhos universitários explicam esta presença constante na imprensa. Esta repercussão influencia diretamente na agenda de eventos e de protestos, por isso a necessidade de inclusão deste módulo.

Os eventos ocorridos na PUC que serão analisados são: organização do dia internacional da mulher, o debate entre Flávio Bolsonaro e Tarcísio Motta e a ocupação do pilotis da PUC-Rio. Estes formam o módulo evento. Paralelamente analisaremos o módulo protesto, que é ligado diretamente ao módulo evento.

A criação dos coletivos e as eleições do DCE foram os outros dois módulos utilizados na metodologia. Assim poderemos inferir a implicação de um evento e sua repercussão na criação dos coletivos e nas eleições do DCE. Espera-se perceber se e como o CM participou desta mudança.

Estas relações entre os acontecimentos ficarão mais claras com a apresentação do processtracing que demonstrará visualmente a relação entre todos os módulos. Os módulos foram divididos em cores, cada número indica um acontecimento e as setas a direção de causalidade. Os atos são tendencialmente sequenciais ( 9 vem antes de 12, ou seja o debate já citado foi anterior à criação do coletivo nuvem negra).

\section{A LUTA POLÍTICA DAS MULHERES NA PUC-RIO}


A escolha desta metodologia foi feita pois espera-se que auxilie na análise da participação das mulheres na transformação dos movimentos sociais na PUC-Rio. Toda a análise a seguir teve seu ponto de partida no método do process-tracing, que permitiu encadear os acontecimentos de maneira a aumentar a capacidade explicativa.

Quando da criação do CM o Brasil atravessava um grande debate sobre a representatividade das mulheres na política, culminando com a publicação da lei 12.034 de 2009, chamada lei dos partidos políticos. Por meio dela, os partidos passaram a ser obrigados a preencher o mínimo de 30\% e o máximo de 70\% para candidaturas de cada sexo. O DCE da PUC-Rio era composto por integrantes da esquerda, em especial do Partido dos Trabalhadores. Na chapa havia poucas mulheres e estas participaram da criação do CM. Neste contexto o CM é criado como uma nova alternativa de luta política das mulheres na universidade.

Até o ano de 2014 o movimento articulou de forma intrínseca com o DCE, porém esta ruptura aconteceu com a mudança de chapa em 2014, com a vitória da chapa Muda, de direita. Esta modificação na orientação política do DCE foi decorrente da grande mobilização da campanha eleitoral de Aécio Neves dentro da PUC-Rio contra a Dilma em sua reeleição. Os alunos de direita se mobilizaram para o Aécio, perderam a eleição presidencial mas a articulação permitiu a vitória no DCE.

A ruptura entre o CM e o DCE foi provocada para o CM ter mais autonomia, tendo em vista que as mulheres que frequentavam estes movimentos serem, politicamente, mais à esquerda. A indignação pela vitória da direita pelas frequentadoras do CM provocou o debate e articulação política. Formou-se assim a necessidade dos membros da antiga chapa perdedora, que era de esquerda, e as mulheres do CM, atuarem de forma mais intensa no campus, mesmo não estando com cargos eletivos do DCE.

Já no começo do ano letivo de 2015 o CM organizou a "semana do dia internacional da mulher". A divulgação deste evento provocou muitas e severas críticas da Igreja Católica e de conservadores, pois abordava temas como o aborto. Este evento causou muitos protestos dentro e fora da universidade, todavia fortaleceu o CM. Este fortalecimento foi causado pela maior articulação entre as integrantes em face de adversidades.

Como primeiro importante evento o novo DCE (chapa MUDA) realizou um debate com Flávio Bolsonaro e Tarcísio Motta. Este evento mobilizou intensamente o campus e lotou o ginásio, que tem capacidade para 5.000 pessoas. Eu tentei comparecer e fiquei escutando o debate e os muitos gritos de apoio e de protestos as duas partes de muito longe, pois estava extremamente cheio. 
Vários grupos se reuniram para organizar protestos contra este debate, alegando que o discurso de ódio e fascismo não poderiam entrar na universidade. Estas reuniões contra o debate eram frequentadas por integrantes do $\mathrm{CM}$ e de outros estudantes que não tinham pertencimento a nenhum grupo. Estes estudantes "sem grupo" perceberam que tinham iguais demandas, gerando a criação do coletivo Nuvem Negra (composto de alunos negros) em abril de 2015 e um mês depois do coletivo Madame Satã, cujos integrantes são homossexuais e pobres da PUC-Rio.

Percebe-se que o debate fortaleceu a união dos estudantes de esquerda com base nas identidades e o reconhecimento de lutas. Gays, negros e mulheres se fortaleceram com a união e formaram coletivos. Estes se tornaram muito populares e atuantes no campus. Importante ressaltar que todos os coletivos, quando da sua criação, eram frontalmente contra os membros eleitos do DCE. Havia a união dos coletivos em busca de representatividade junto à instituição. Além disso os membros dos coletivos lutavam contra um único adversário político: a chapa MUDA, que estava no DCE.

Todavia esta mobilização não foi o suficiente para, no final do ano de 2015, impedir a reeleição da chapa Muda para o DCE. A chapa contrária - Renova - era composta por representantes dos coletivos. Apesar da grande disputa e pequena diferença entre as chapas, os estudantes com orientação política mais à direita continuaram no poder.

O ano de 2016 foi marcado pela quantidade de novos coletivos, como o coletivo Bastardos da PUC e o coletivo Vila, este em sua descrição já definia que era composto pela esquerda da PUCRio. A união desses novos coletivos com os já existentes mobilizou a ocupação dos pilotis, onde os universitários acamparam no prédio principal da PUC-Rio. Eles dormiam em barracas e durante o dia propuseram várias atividades. Chamaram muitos políticos de esquerda, ativistas dos Direitos Humanos e professores de dentro e de fora da universidade para dar aulas públicas, palestras e realizar debates ${ }^{4}$.

Importante ressaltar que houve uma assembleia sobre o início da ocupação, onde o DCE se manifestou contrário. Houve a publicação de uma nota pública que o DCE se definia como indignado por sua posição não ser respeitada, tendo em vista ser o representante do corpo discente. A resposta dos animadores da ocupação foi que eles não queriam mais representantes, que estavam fazendo política de forma direta, assim como nos coletivos. Percebe-se que a horizontalidade existente nos coletivos permitiu que os universitários se manifestassem desta maneira.

\footnotetext{
4 A vereadora executada Marielle Franco, ex aluna da PUC-Rio compareceu na ocupação e leu uma moção de apoio ao coletivo Bastardos.
} 
Este evento ocupou fisicamente a universidade durante um mês. Durante a ocupação ocorreu a eleição do DCE, com a vitória da chapa Renova, composta pelos membros dos coletivos e de integrantes de esquerda. Percebe-se como a ocupação foi importante para a conquista do DCE.

A ocupação não teve líderes nomeados, oficiais. Todavia percebia-se que os maiores animadores eram membros de um - ou mais - coletivos. Inclusive as reuniões dos coletivos ocorriam dentro do espaço da intervenção. Entre estes estudantes as integrantes do CM estavam atuando de forma ativa e com protagonismo, como consequência a chapa vencedora do DCE era composta por mais de $50 \%$ de mulheres.

\section{CONCLUSÃO}

De acordo com Kergoat "o que pode de fato questionar as relações sociais de sexo são as práticas sociais coletivas: por exemplo, decisões como quais as mulheres que terão as responsabilidades formais (presidência da associação) e práticas (responsabilidades organizacionais durante as manifestações), ou a decisão de que haja um aprendizado coletivo em situações de fala diante de um público etc" (KERGOAT, 2010, p.95). Nessa perspectiva, as mulheres, ao buscarem seu espaço no universo da política acadêmica, passam a ter poder de ação na construção e desenvolvimento dessas relações sociais, o que interfere na imagem imposta de feminilidade. Se as práticas sociais coletivas podem questionar as relações de poder (KERGOAT, 2010), o CM pode ser um espaço de fala que as integrantes possuem para tomarem decisões e romperem com os velhos mecanismos da política. Estas são práticas que permanecem nas relações sociais ao longo do tempo, sendo a figura masculina referência de lugar de fala e dominação. O CM pode ser utilizado como um meio para romper com a dinâmica da dominação masculina, possibilitando que as relações intersubjetivas e sociais possam modificar as práticas sociais.

Percebe-se como a discussão em torno da lei do partido político modificou não apenas o cenário político tradicional, como também o universitário. Todavia a forma que ocorreu foi diferente do esperado, não com a implementação de cotas nas chapas do DCE, mas uma nova forma de fazer política: os coletivos universitários. Esta nova forma de fazer política estudantil tem como característica relações de poder não verticalizadas, como na política tradicional, característica do patriarcado. As relações de poder dos coletivos universitários são horizontais, onde se busca a representatividade e atuação política de forma direta. 


\section{BIBLIOGRAFIA}

GOMIDE, Raphael. O PSDB ganhou... no terceiro turno da PUC: Na tradicional universidade carioca, alunos de orientação liberal quebram o domínio político da esquerda. 2015. $<$ https://epoca.globo.com/tempo/noticia/2015/01/o-psdb-ganhou-bno-terceiro-turno-dapucb.html>

GOHN, Maria da Glória. Movimentos sociais na contemporaneidade. Rev. Bras. Educ., Rio de Janeiro , v. 16, n. 47, p. 333-361, ago. 2011 . Disponível em<http:/ /www.scielo.br/scielo.php?script=sci_arttext\&pid=S1413-

24782011000200005\&lng=pt\&nrm=iso $>$. acessos em 28 maio 2018. http://dx.doi.org/10.1590/S1413-24782011000200005.

KERGOAT, Danièle. Dinâmica e consubstancialidade das relações sociais. Novos estud. CEBRAP, São Paulo, n. 86, p. 93-103, Mar. 2010.

PAIVA, Angela Randolpho et al (Org.). Movimentos sociais e teoria crítica: notas sobre a redemocratização brasileira In: D'ARAUJO, Maria Celina Soares. Redemocratização e mudança social no Brasil. Rio de Janeiro: Fgv, 2014. Cap. 22431004. p. 5-5.

PUC-RIO, Dce Raul Amaro. Centros Acadêmicos. Disponível em: $<$ http://dcepucrio.org/novo/>. Acesso em: 06 jun. 2017 
ANEXO 1 - PROCESS-TRACING

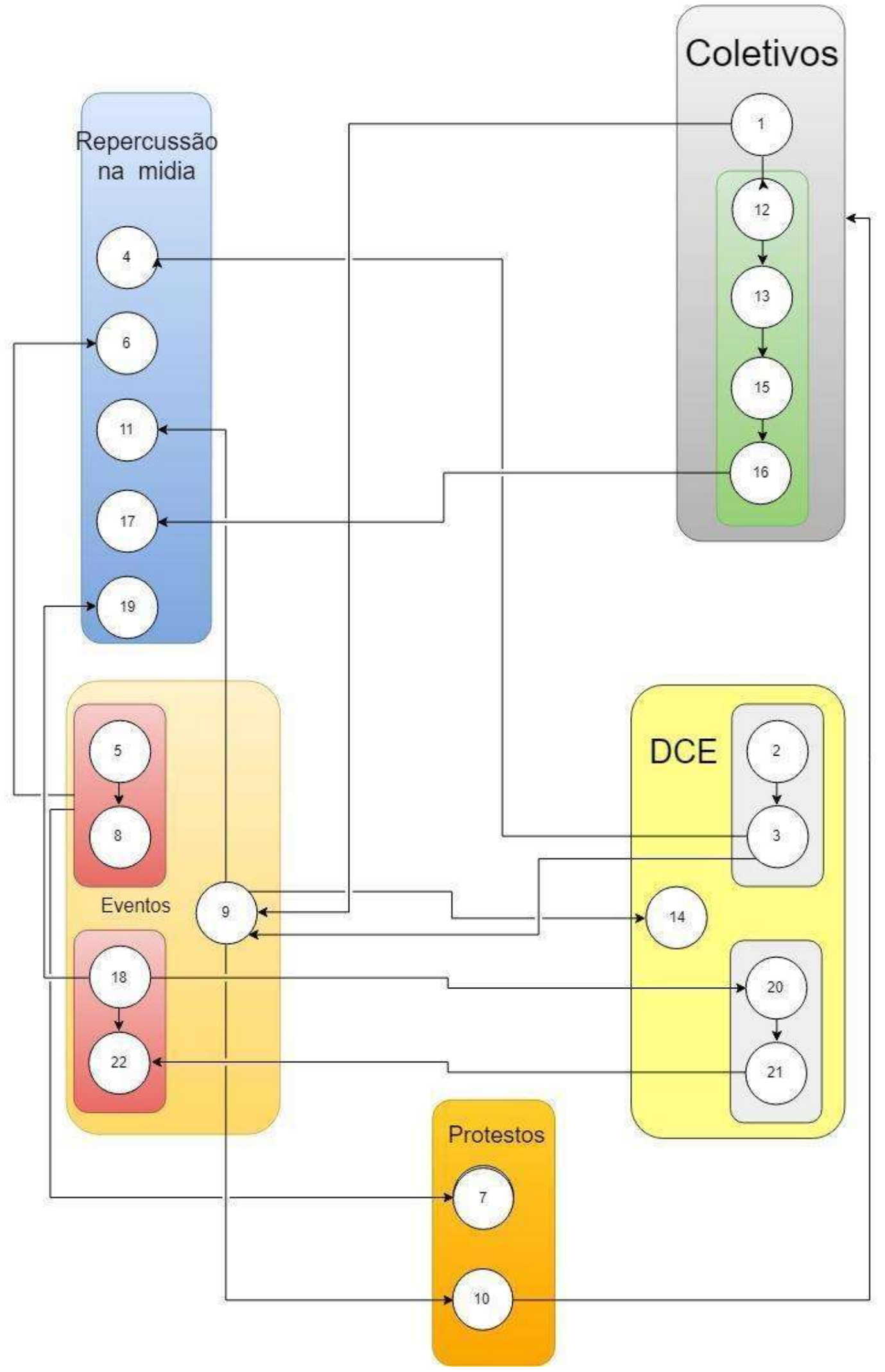




\begin{tabular}{|c|c|}
\hline 1 & 2009 - Criação do Coletivo de mulheres da PUC-Rio \\
\hline 2 & $\begin{array}{c}2014 \text { - Gestão da chapa Roda Viva. Chapa de esquerda com muitos membros do } \\
\text { PT }\end{array}$ \\
\hline 3 & 26/11/14 - Eleição do DCE Vitória da Chapa Muda \\
\hline 4 & $\begin{array}{l}\text { 30/11/2014 - Ancelmo Góis publicou uma nota intitulada "Aécio venceu na } \\
\text { PUC". No texto, o jornalista afirma ainda que a chapa é "próxima ideologicamente } \\
\text { dos tucanos". }\end{array}$ \\
\hline 5 & $\begin{array}{l}\text { 02/15 - Organização da Semana do Dia Internacional da Mulher promovido pelo } \\
\text { CASOC e pelo Coletivo de Mulheres da PUC-Rio }\end{array}$ \\
\hline 6 & $\begin{array}{l}\text { 24/02/2015 - Matéria do Jornal O GLOBO "Católicos criam petição contra } \\
\text { evento da PUC-Rio que celebrará o Dia Internacional da Mulher" }\end{array}$ \\
\hline 7 & 02/15 - Grande protesto da ala conservadora da Igreja Católica \\
\hline 8 & $\begin{array}{c}\text { 03/2015 - Semana do Dia Internacional da Mulher promovido pelo CASOC. } \\
\text { Evento despertou grande protesto da ala conservadora da Igreja Católica. Evento } \\
\text { ocorreu sob protesto e com alteração na programação. }\end{array}$ \\
\hline 9 & $\begin{array}{l}\text { 25/03/2015 - debate entre o deputado estadual Flávio Bolsonaro (PP) e o } \\
\text { professor Tarcísio Motta lotou o Ginásio com cerca de mil e } 700 \text { alunos. }\end{array}$ \\
\hline 10 & 25/03/15 - Grande manifestação contra o Debate \\
\hline 11 & $\begin{array}{l}\text { 26/03/15 - Matéria no Portal R7 Rio: Debate entre Tarcísio (Psol) e Bolsonaro } \\
\text { (PP) sobre desmilitarização da PM acaba em briga de militantes }\end{array}$ \\
\hline 12 & 02/04/2015 - Criação do Coletivo Nuvem negra \\
\hline 13 & 05/2015 - Criação do Coletivo Madame Satã \\
\hline 14 & 11 e 12/11/2015 - Eleição do DCE: Vitória Chapa Muda \\
\hline
\end{tabular}




\begin{tabular}{|c|c|}
\hline 15 & 18/02/2016 - Criação do facebook do Coletivo Vila \\
\hline 16 & 08/09/16 Criação do Coletivo Bastardos da PUC \\
\hline 17 & $\begin{array}{l}\text { 06/10/2016 - BBC publica a matéria: ‘A professora não gostava de pobre’' } \\
\text { bolsistas criam página contra preconceito em universidade carioca }\end{array}$ \\
\hline 18 & 16/11/2016 - Início das ocupações do Pilotis \\
\hline 19 & $\begin{array}{c}\text { 17/1/2016 - Matéria do Jornal O GLOBO - Com barracas, alunos ocupam a PUC- } \\
\text { Rio contra PEC do teto de gastos }\end{array}$ \\
\hline 20 & 17/11/2016 - Declaração do DCE gestão MUDA contrário a ocupação \\
\hline 21 & 23 e 24/11/2016 - Eleição do DCE. Vitória da Chapa Renova \\
\hline 22 & 18/12/2016 - Fim da ocupação do Pilotis \\
\hline
\end{tabular}

